\section{Ancient paradox}

\section{Lawrence Guy Straus}

Thoughtful Foragers. By Steven J. Mithen. Cambridge University Press: 1990. Pp.289. £35, \$59.50.

IT IS refreshing to read the work of someone with ambitious intellectual goals, someone who not only achieves most of them, but does so with healthy self-doubts and a sense of humour. Mithen tries to bridge the gulf between materialist processual archaeology and the selfproclaimed radical post-processual variety. In this dissertation-turned-book, he seeks to explain why Mesolithic hunters in northern Europe killed specific game animals and why Upper Palaeolithic hunters in southern Europe painted caves. Although the first question may be a bit esoteric (unless you follow the burgeoning literature on hunter-gatherer ecology and optimal-foraging theory), the second is one of the most hotly debated among prehistorians. Mithen's "audacity" in tackling these questions is great: although some of the results of his work are shaky, by and large his suggestions make sense, even if they do not provide the whole answer.

Mithen's argument is an eclectic, usually convincing combination of game theory in the guise of "eco-psychology", ethnographic analogy, game ecology, modified optimal foraging theory, Mesolithic and Upper Palaeolithic archeology, and computer simulation. The key argument involves the obvious fact that the archaeological record is (partly) the product of decisions made by anonymous, individual humans. His book is an attempt by a practical archaeologist to reconcile

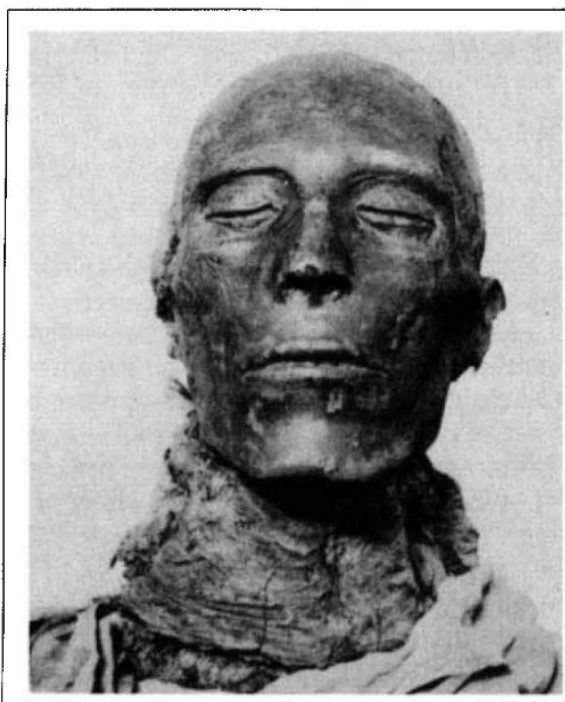

Father and son - the mummies of Seti 1 (above) and his son Ramesses II (right). The World of the Pharaohs: A Complete Guide To Ancient Egypt by Christine Hobson offers a fascinating glimpse of the lives of both the pharaohs of Egypt themselves, and the explorers who discovered their tombs. Published by Thames and Hudson, price is $\$ 14.95$ (pbk). the fact that hunter-gatherers had to eat with the demands of the post-processualists that individuals operate in a world of symbols and social status. Let us not kid ourselves, however; Mithen is looking at statistical patterns. Individual Stone Age hunters as a group still did act rationally in the long run, even if Mithen does acknowledge, refreshingly, that individuals often miscalculated, erred, operated on the basis of imperfect information, and so on - just like their modern counterparts. (In this vein, I found the book more realistic than much of the more abstract literature on optimal foraging.)

One of the paradoxes of Thoughtful Foragers (I picture Rodin's "Thinker" seated on a coastal rock, bow on his knee, contemplating a distant stag and a nearby limpet shell) is the argument that Mesolithic hunters in Sweden were engaged in fierce interpersonal rivalry as to who was the greater killer, whereas on the other hand the Upper Palaeolithic people of southern France and northern Spain stressed cooperation. I find the competition aspect of the Mesolithic argument a bit strained, although Mithen obtains a nice fit between his simulated meliorizing model and the faunal assemblages from Swedish sites (in, supposedly, an optimum-foraging environment). I am more dubious about the early Holocene environments along the south German Danube being as poor as Mithen thinks. And many of the Mesolithic faunal assemblages are so small as to make some of the supposed fits highly questionable.

As one of the producers of much of the data Mithen uses for his analyses of Upper Palaeolithic subsistence in Cantabrian Spain, I am gratified that the hypothesis of intensification by means of diversification and specialization I first published in 1977

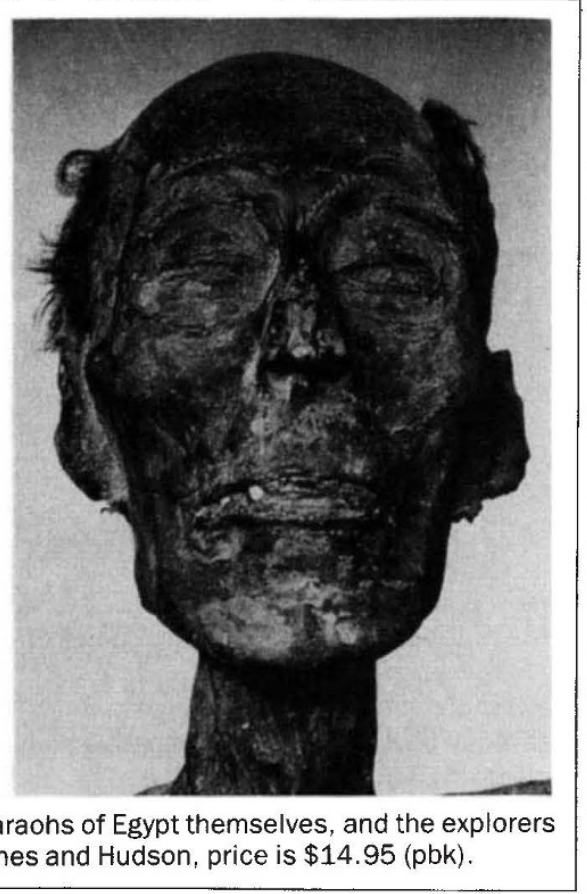

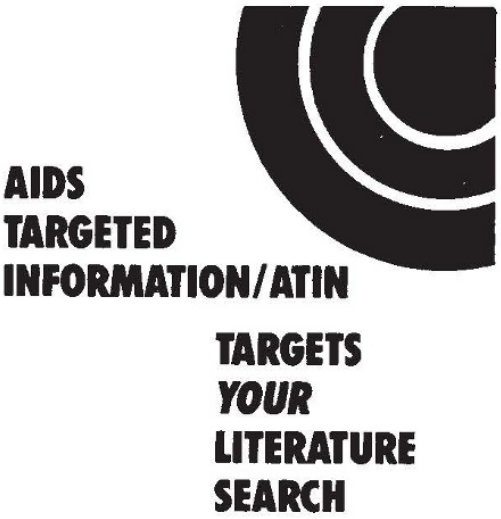

Expand your base of knowledge about AIDS/HIV with AIDS Torgeted INformation/ATIN. Every month, ATIN not only provides abstracts but also indepth evaluations of the current published scientific literature on AIDS. Written by clinicians and researchers for clinicions and researchers, ATIN provides an

刃 苋 () กั z $\overrightarrow{\mathrm{c}}$ Sponsored by the American Fou $\omega$ for AIDS Research (AmFAR).

is confirmed by Mithen's manipulations. I also agree that much (although not all) of the cave art of the region has to do with the storage and transgenerational transmission of information critical to hunting success under conditions of long-term climatic and prey population instability during the Upper Pleniglacial and Late Glacial. The art (among many other things) undoubtedly does contain cues, mnemomic aids for saga-tellers. Whether this has to do with switching between game drives and stalking, as Mithen thinks, is a bit more problematical. (I could make counter-arguments for aspects of his case, but space prohibits it.) Suffice it to say that I found the arguments stimulating and the use made of our data worthwhile. The text and bibliography suffer from numerous typographical errors (regrettable, given the book's steep price). Mithen seems to have little firsthand Spanish experience; a dose thereof would be good!

Mithen's work should be read and thought about both by armchair theoreticians and by those of us who try to keep producing hard data on chronology, subsistence, technology and settlement as well as on prehistoric social organization and belief systems.

Lawrence Guy Straus is in the Department of Anthropology, University of New Mexico, Albuquerque, New Mexico 87131, USA. 